\title{
A 5- to 8-year randomized study on the treatment of cervical radiculopathy: anterior cervical decompression and fusion plus physiotherapy versus physiotherapy alone
}

\author{
Markus Engquist, MD, PhD, ${ }^{1}$ Håkan Löfgren, MD, PhD, ${ }^{3}$ Birgitta Öberg, PhD, RPT, ${ }^{4}$ \\ Anders Holtz, MD, PhD, ${ }^{5}$ Anneli Peolsson, PhD, RPT, ${ }^{4}$ Anne Söderlund, PhD, RPT, ${ }^{6}$ \\ Ludek Vavruch, MD, PhD, ${ }^{3}$ and Bengt Lind, MD, PhD ${ }^{2,7}$
}

\begin{abstract}
${ }^{1}$ Department of Orthopaedics, Ryhov Hospital; ${ }^{2}$ Department of Orthopaedics, Institute of Clinical Sciences, Sahlgrenska Academy, University of Gothenburg; ${ }^{3}$ Neuro-Orthopedic Center, Ryhov Hospital, Jönköping; ${ }^{4}$ Department of Medical and Health Sciences, Division of Physiotherapy, Faculty of Health Sciences, Linköping University, Linköping; ${ }^{5}$ Department of Neuroscience, Neurosurgery, Uppsala University Hospital, Uppsala; ${ }^{6}$ Department of Physiotherapy, School of Health, Care and Social Welfare, Mälardalen University, Västerås; and 7 Spine Center Göteborg, Gothenburg, Sweden
\end{abstract}

\begin{abstract}
OBJECTIVE The aim of this study was to evaluate the 5- to 8-year outcome of anterior cervical decompression and fusion (ACDF) combined with a structured physiotherapy program as compared with that following the same physiotherapy program alone in patients with cervical radiculopathy. No previous prospective randomized studies with a follow-up of more than 2 years have compared outcomes of surgical versus nonsurgical intervention for cervical radiculopathy.

METHODS Fifty-nine patients were randomized to ACDF surgery with postoperative physiotherapy (30 patients) or to structured physiotherapy alone (29 patients). The physiotherapy program included general and specific exercises as well as pain coping strategies. Outcome measures included neck disability (Neck Disability Index [NDI]), neck and arm pain intensity (visual analog scale [VAS]), health state (EQ-5D questionnaire), and a patient global assessment. Patients were followed up for 5-8 years.
\end{abstract}

RESULTS After $5-8$ years, the NDI was reduced by a mean score $\%$ of $21(95 \% \mathrm{Cl} 14-28)$ in the surgical group and $11 \%(95 \% \mathrm{Cl} 4 \%-18 \%)$ in the nonsurgical group $(p=0.03)$. Neck pain was reduced by a mean score of $39 \mathrm{~mm}(95 \% \mathrm{Cl}$ $26-53 \mathrm{~mm}$ ) compared with $19 \mathrm{~mm}(95 \% \mathrm{Cl} 7-30 \mathrm{~mm} ; \mathrm{p}=0.01)$, and arm pain was reduced by a mean score of $33 \mathrm{~mm}$ $(95 \% \mathrm{Cl} 18-49 \mathrm{~mm})$ compared with $19 \mathrm{~mm}(95 \% \mathrm{Cl} 7-32 \mathrm{~mm} ; \mathrm{p}=0.1)$, respectively. The EQ-5D had a mean respective increase of $0.29(95 \% \mathrm{Cl} 0.13-0.45)$ compared with $0.14(95 \% \mathrm{Cl} 0.01-0.27 ; \mathrm{p}=0.12)$. Ninety-three percent of patients in the surgical group rated their symptoms as "better" or "much better" compared with $62 \%$ in the nonsurgical group ( $p=$ 0.005). Both treatment groups experienced significant improvement over baseline for all outcome measures.

CONCLUSIONS In this prospective randomized study of 5- to 8-year outcomes of surgical versus nonsurgical treatment in patients with cervical radiculopathy, ACDF combined with physiotherapy reduced neck disability and neck pain more effectively than physiotherapy alone. Self-rating by patients as regards treatment outcome was also superior in the surgery group. No significant differences were seen between the 2 patient groups as regards arm pain and health outcome. http://thejns.org/doi/abs/10.3171/2016.6.SPINE151427

KEY WORDS cervical radiculopathy; randomized; surgery; physiotherapy; anterior cervical decompression and fusion; outcome

$\Lambda$ NTERIOR cervical decompression and fusion (ACDF) is a commonly performed surgical procedure for patients suffering from neck and arm pain due to cervical radiculopathy. Some earlier studies have reported about $80 \%$ patient satisfaction and a $30-\mathrm{mm}$ reduc- tion in pain intensity on the visual analog scale (VAS) after surgery. $5,12,13,20,24$ However, these studies were conducted without a control group of nonsurgical patients ${ }^{5,12,13,20}$ or with a nonstructured nonsurgical treatment alternative..$^{20}$ Previously, we reported the 2-year outcome of a random-

ABBREVIATIONS ACDF = anterior cervical decompression and fusion; NDI = Neck Disability Index; VAS = visual analog scale.

SUBMITTED January 7, 2016. ACCEPTED June 9, 2016.

INCLUDE WHEN CITING Published online August 26, 2016; DOI: 10.3171/2016.6.SPINE151427. 
ized trial in which ACDF combined with a comprehensive physiotherapy program was compared with the same physiotherapy program alone. ${ }^{9}$ The outcomes favored the surgical group at 1 year, but the only statistically significant difference between the groups on repeated-measures ANOVA for the entire 2-year study period was the lesser neck pain in the surgically treated patients. Both favorable outcomes up to 22 years following ACDF and deterioration over time have been reported, ${ }^{11,13,18}$ but there are no randomized long-term studies comparing ACDF with nonsurgical treatment.

In this paper, we report the 5- to 8-year outcomes from our earlier study comparing surgery combined with physiotherapy and physiotherapy alone to treat cervical radiculopathy, with a focus on neck disability, patient global assessment, health outcome, and pain.

\section{Methods}

Sixty-three patients, 18-65 years old, with cervical radiculopathy who had elected surgical treatment at 3 Swedish spine centers were included in the study. Patients were provided with oral and written information about the study and signed informed consent forms. The Regional Ethical Review Board at the Faculty of Health Sciences in Gothenburg approved the study, and the experiments complied with the current laws of Sweden. The study period ranged from June 2003 to February 2009.

Study inclusion criteria were pain (with or without sensory and/or motor deficit) in one or both arms indicating either nerve root involvement caused by MRI-confirmed disc herniation with or without osteophytes, or stenosis caused by osteophytes, a symptom duration of 8 weeks to 5 years, symptoms involving 1 or 2 disc levels, and a patient age of 18-65 years. Exclusion criteria were myelopathy, history of neck distortion (whiplash-associated disorder) or "generalized" muscle pain (for example, fibromyalgia), indication for a different type of cervical spine surgery (for example, vertebral body resection or foraminotomy), malignancy, inflammatory joint disease, psychiatric disorder, concurrent work-disabling disease, other spinal disease causing pain or neurological deficit during the last year, and prior cervical spine surgery.

All 63 patients completed the study at 2 years and were then asked to fill out another questionnaire at least 5 years after inclusion in the study. The mean follow-up time was 70 months (SD 10 months, range 57-92 months).

Fifty-five patients returned the 5-year questionnaire, and another 4 answered the questions by phone. Of the remaining 4 patients, 2 declined further participation and 2 could not be reached. Thus 59 patients, 29 females and 30 males, were included in the present 5- to 8-year follow-up study. The mean patient age was 46 years (SD 9). Until the 2-year follow-up, the patients were followed up via personal meetings with an unbiased observer who had access to their medical records, making sure no subsequent surgery was missed. At the 2-year follow-up, 5 patients originally randomized to nonsurgical treatment had undergone surgery at their own request. Four of them are included in this follow-up study. On the 5- to 8-year follow-up questionnaire, there was a question about whether the patient had undergone any cervical spine surgery since the 2-year follow-up. All patients answered this question, and only 3 (all originally randomized to nonsurgical treatment) answered yes, resulting in a total of 7 patients (24\% of the nonsurgical group) who crossed over prior to the final follow-up. No patients originally randomized to surgery underwent a second cervical spine procedure during the study period. A flow chart of the study is presented in Fig. 1. The data presented here reflect patients included in the same group to which they were originally randomized. The present study focused on changes occurring between baseline and the 5- to 8-year follow-up, whereas the outcomes for the 3 follow-ups between baseline and 2 years posttreatment have been published elsewhere. ${ }^{9}$ We also present data for any changes occurring between the 2- and 5- to 8-year follow-ups.

\section{Randomization and Treatment}

After agreeing to participate in the study and providing informed consent, patients completed the baseline questionnaires. Equal numbers of centrally stored, randomly distributed sealed envelopes were then used to randomize patients into 1 of 2 treatment groups. For administrative reasons, treatment for both groups, as described below, was initiated approximately 6 weeks following randomization. The rates of adherence to physiotherapy treatment (that is, $>80 \%$ of the occasions) were $94 \%$ in the nonsurgical group and $73 \%$ in the surgical group, and the difference between the two was not statistically significant $(\mathrm{p}=$ 0.09 ). No restrictions or changes in the use of medication were stipulated by the study protocol in any of the treatment groups. The symptomatic and/or treated levels are shown in Table 1.

\section{Surgical Group}

Anterior cervical decompression and fusion (ACDF) was performed by 1 of 4 participating experienced senior surgeons specialized in cervical spine surgery. One-level fusion (26 patients) was performed using cylindrical titanium implants (BAK/C, Zimmer). Two-level fusion (4 patients) was accomplished using 2 metal cages along with an anterior plate to achieve primary stability. No iliac crest bone grafts or other bone substitutes were used. The patients received standard care instructions from the physiotherapist before hospital dismissal. Three months postsurgery, patients began the same physiotherapy program used by the nonsurgical group (see below), which was then continued for a minimum of 3 months. The 3-month time interval prior to initiating physiotherapy was chosen to allow the fusion to heal. At the 3-month clinical and radiological follow-up, the surgeon considered all segments involved in fusion to be healed given the lack of movement of the fused segments on flexion and extension radiographs. No further evaluation of fusion rate was performed in the study.

\section{Nonsurgical Group}

Physiotherapy treatment (29 patients) was customized based on a structured program. Medical exercise therapy focused on neck stabilization and endurance combined 


\section{Inclusion, informed consent, baseline questionnaire}

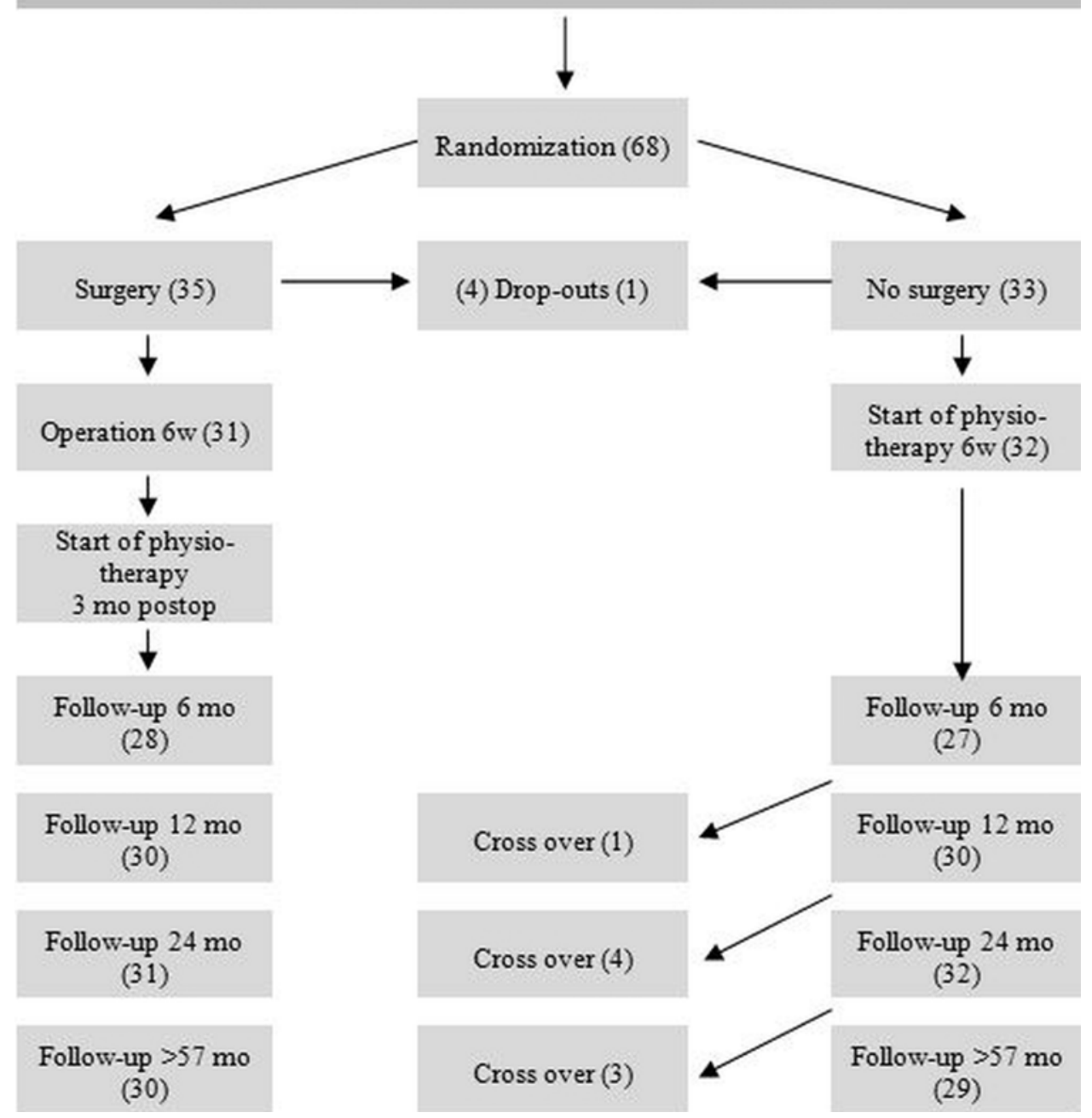

FIG. 1. Flow chart of the study design. Five patients dropped out before the start of treatment and were excluded; 4 of them had been randomized to surgery. Eight patients in the nonsurgical group were operated on during the study. One underwent surgery after the 6-month follow-up, 4 after the 12-month follow-up, and 3 after the 24-month follow-up. Seven of these patients were included in this 5 - to 8 -year follow-up of 59 patients. $w=$ weeks.

with relaxation training and procedures for pain relief. General exercise and physical activity were gradually added and encouraged for future use. Additional strategies included education and training in coping with pain, increasing self-efficacy, and stress management. Patients performed the program at home daily and at the clinic twice weekly, continuing for a minimum of 3 months. The specific treatment each patient received was individually recorded. A more detailed description of the program has been previously published. ${ }^{19}$

\section{Evaluation}

The baseline questionnaires in the original study were filled in prior to randomization. Follow-up was undertaken by an observer who was not involved in patient treatment, and questionnaires were filled in between 5 and 8 years (mean 70 months, range 57-92 months) after original study inclusion. The primary outcome measure of the study was self-reported neck disability, and secondary measures were self-reported pain intensity, global assessment, and health state.

The following methods and protocols were used: 1) Neck disability was assessed using the Neck Disability Index (NDI). ${ }^{1,27,29}$ 2) Pain intensity for "present pain" was registered using a horizontal VAS from 0 to $100 \mathrm{~mm}$,

TABLE 1. Symptomatic and/or treated levels in patients with cervical radiculopathy

\begin{tabular}{lccc}
\hline \multicolumn{1}{c}{ Level } & Nonsurgical Group & Surgical Group* & Total \\
\hline C4-5 & 1 & 0 & 1 \\
\hline C5-6 & 14 & 12 & 26 \\
\hline C6-7 & 11 & 13 & 24 \\
\hline C7-T1 & 0 & 1 & 1 \\
\hline C5-6 \& C6-7† & 3 & 4 & 7 \\
\hline
\end{tabular}

* For the surgical group, the values represent the operated levels.

$†$ All 2-level cases involved C5-6 and C6-7. 
where $0 \mathrm{~mm}$ represented "no pain" and $100 \mathrm{~mm}$ indicated the "worst pain imaginable." Neck pain and arm pain were recorded separately. 3) Patient global assessment required the patient to indicate the appropriate response to the statement, "After treatment, my neck/arm problems are: much better, better, unchanged, worse, much worse." In the analysis, answers were dichotomized into 2 groups: "better/much better" or "unchanged/worse/much worse." 4) Health state was assessed with the EQ-5D questionnaire, ${ }^{10}$ consisting of 5 health-related questions, which were converted to a score ranging between -0.584 and 1 , where 1 was interpreted as the "best imaginable health state" and 0 as the "worst imaginable health state" or death. Although negative values are rare, they should be interpreted as "a condition worse than death." The EQ-VAS 0-100, in which 0 is characterized as the "worst imaginable health state" and 100 as the "best imaginable health state," was also used.

\section{Statistical Analysis}

Differences at baseline and differences in changes from baseline to 5-8 years between the 2 treatment groups were analyzed using Pearson's chi-square test on categorical data and independent sample t-test on interval level data.

Differences within groups from baseline to 5-8 years as well as between 2 and 5 years were analyzed using the paired samples t-test. Risk ratios with corresponding 95\% confidence intervals were calculated for treatment group differences in the patient's global assessment, and significance was tested using z-statistics. In the analysis, the data for patients who crossed over from nonsurgical to surgical treatment were kept in the group that the patients were originally randomized to. All tests were 2-sided, and the significance level was set to $\mathrm{p}<0.05$.

\section{Results}

Socio-demographic and baseline data are presented in Table 2. There were no significant differences between treatment groups at baseline regarding these data. Results from earlier follow-ups, as well as a comparison with the data for 37 analyzed eligible but nonparticipating patients, have been reported elsewhere. ${ }^{911}$ Compared with the nonparticipants, study participants had a significantly longer duration of neck symptoms and lower pain levels, but no differences were detected concerning other baseline data. There were no early complications (for example, unexpected bleeding, infection, onset of neurological deficit, or thromboembolism) related to the surgical procedures. No reoperations motivated by nonunion or any other reason were performed during the study period.

\section{Neck Disability}

At 5-8 years the NDI declined by a mean score $\%$ of 21 in the surgery group and 11 in the nonsurgery group compared with baseline scores, a statistically significant difference in favor of the surgery group $(p=0.03)$. The decline in the NDI compared with baseline scores was significant in both treatment groups. These data are presented in Tables 3 and 4 and Fig. 2A.
TABLE 2. Socio-demographic data of patients with cervical radiculopathy, before randomization to treatment*

\begin{tabular}{|c|c|c|c|}
\hline Parameter & $\begin{array}{c}\text { Surgical } \\
\text { Group }\end{array}$ & $\begin{array}{c}\text { Nonsurgical } \\
\text { Group }\end{array}$ & $\mathrm{p}$ Value \\
\hline No. of patients & 30 & 29 & \\
\hline Age in yrs & $48(8)$ & $44(9)$ & NS $\ddagger$ \\
\hline $\begin{array}{l}\text { Duration of neck symptoms } \\
\text { in mos }\end{array}$ & $15(12)$ & $21(19)$ & NSt \\
\hline $\begin{array}{l}\text { Duration of arm symptoms } \\
\text { in mos }\end{array}$ & $13(10)$ & $16(16)$ & NS $\ddagger$ \\
\hline NDI in \% & $37(14)$ & $40(14)$ & NS $\ddagger$ \\
\hline $\begin{array}{l}\text { VAS neck pain score in } \mathrm{mm} \\
\quad(0-100 \mathrm{~mm})\end{array}$ & $50(25)$ & $47(22)$ & NS $\ddagger$ \\
\hline $\begin{array}{l}\text { VAS arm pain score in } \mathrm{mm} \\
\qquad(0-100 \mathrm{~mm})\end{array}$ & $44(26)$ & $45(21)$ & NS $\ddagger$ \\
\hline EQ-5D score $(-0.584$ to 1$)$ & $0.51(0.28)$ & $0.53(0.28)$ & NS $\ddagger$ \\
\hline $\begin{array}{l}\text { EQ-VAS score in } \mathrm{mm} \\
(0-100 \mathrm{~mm})\end{array}$ & $54(20)$ & $46(16)$ & NS $\ddagger$ \\
\hline No. of males (\%) & $13(43)$ & $17(57)$ & NS§ \\
\hline No. of smokers (\%) & $9(33)$ & $5(17)$ & NS§ \\
\hline \multicolumn{4}{|c|}{$\begin{array}{l}\text { NS = not significant }(p>0.05) \text {. } \\
\text { * Values presented as the means }(S D) \text {, unless otherwise noted. } \\
\dagger \text { The } p \text { values represent differences between groups at baseline. } \\
\ddagger \text { Significance was calculated with the independent samples t-test. } \\
\S \text { Significance was calculated with the chi-square test. }\end{array}$} \\
\hline
\end{tabular}

\section{Pain}

The surgical group reported a mean reduction of 39 $\mathrm{mm}$ in neck pain intensity on the VAS compared with 19 $\mathrm{mm}$ in the nonsurgery group, a statistically significant difference in favor of the surgery group $(p=0.01)$. Arm pain intensity declined by a mean of $33 \mathrm{~mm}$ on the VAS in the surgery group and $19 \mathrm{~mm}$ in the nonsurgery group, which did not represent a statistically significant difference $(\mathrm{p}=$ 0.1). Compared with baseline, the reduction in both neck and arm pain intensity was significant in both treatment groups. These data are presented in Tables 3 and 4 and Fig. 2B-C.

\section{Patient Global Assessment}

In the surgical group, 28 of 30 patients rated their symptoms as "better" or "much better" after 5-8 years compared with 18 of 29 in the nonsurgical group. The risk difference for recovery was $31 \%$, and the risk ratio was 1.5 in favor of surgery. The difference was statistically significant $(\mathrm{p}=0.005)$. There was also a difference in the distribution of answers within the group of patients who responded "better" or "much better," in which a significantly larger number of patients in the surgical group rated themselves as "much better" compared with the nonsurgical group $(\mathrm{p}=0.02)$. These data are presented in Tables 5 and 6 .

\section{Health State}

Health state according to EQ-5D increased by a mean score of 0.29 in the surgical group and 0.14 in the nonsurgical group. This difference between treatment groups 

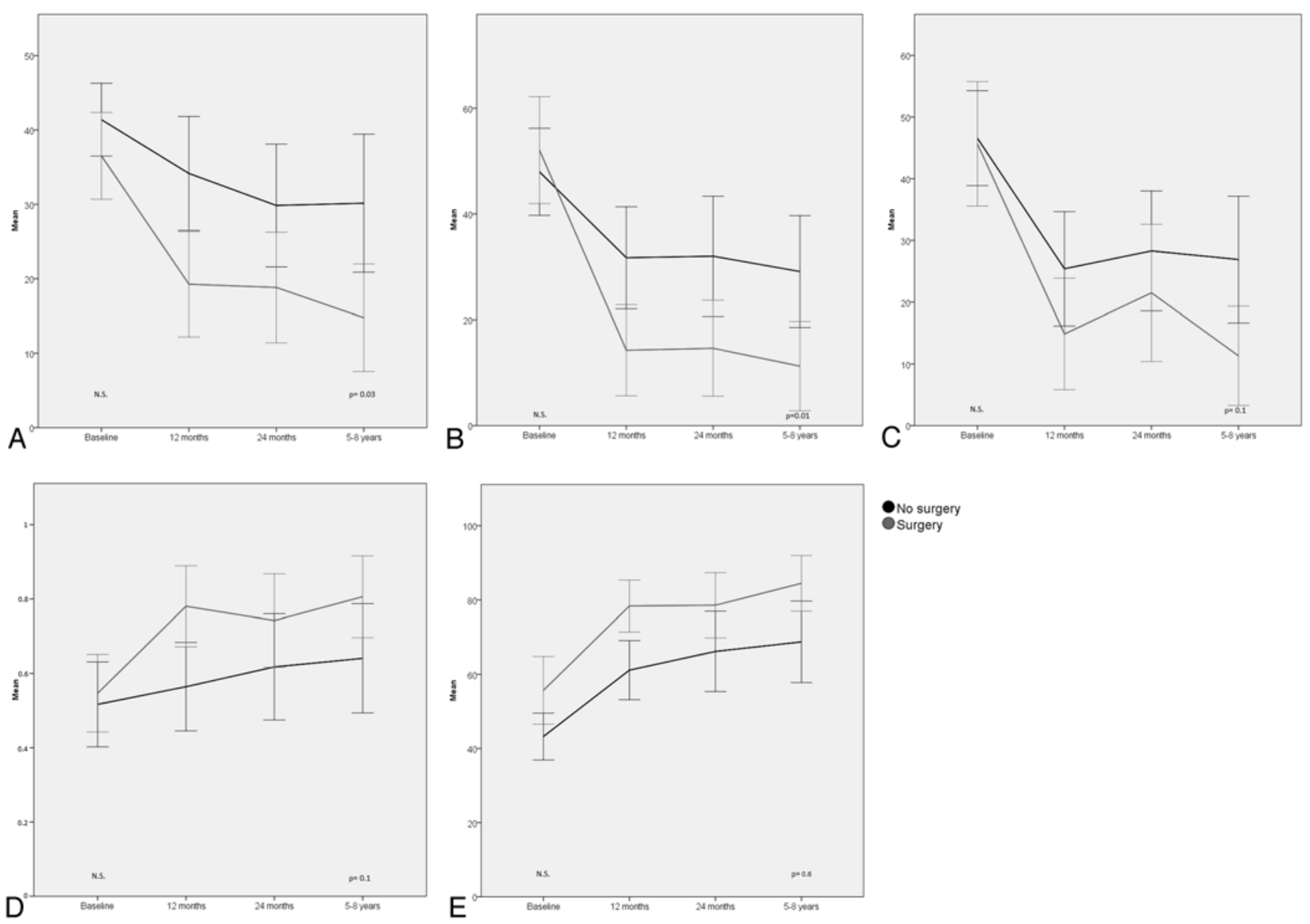

FIG. 2. A: Neck disability index (score $0 \%-100 \%$ ) in both treatment groups from baseline to the last follow-up. B: Neck pain intensity score (VAS 0-100 mm) in both treatment groups from baseline to the last follow-up. C: Arm pain intensity score (VAS 0-100 $\mathrm{mm}$ ) in both treatment groups from baseline to the last follow-up. D: EQ-5D score (-0.584 to 1) in both treatment groups from baseline to the last follow-up. E: EQ-VAS $(0-100)$ in both treatment groups from baseline to the last follow-up. In all graphs, error bars represent the $95 \%$ confidence interval, and p values were calculated using an independent samples t-test.

was not significant $(\mathrm{p}=0.1)$. Health state as estimated by patients on the EQ-VAS increased by a score 29 in the surgical group and 25 in the nonsurgical group, although the difference between the two was not significant $(\mathrm{p}=$ $0.6)$. Both parameters improved significantly in each group compared with baseline. These data are presented in Tables 3 and 4 and Fig. 2D-E.

\section{Comparison Between 2 and 5-8 Years}

Between 2 and 5-8 years, there was still significant improvement in the surgical group for NDI, arm pain intensity, and EQ-VAS. Neck pain intensity and EQ-5D did not show significant changes. In the nonsurgical group, there were no significant changes in any of the outcome measures. No significant differences were detected between the 2 treatment groups when comparing changes in this time interval. These data are presented in Table 7.

\section{Discussion}

In this study of surgical versus nonsurgical treatment in patients with cervical radiculopathy, ACDF combined with physiotherapy was more effective in reducing neck disability and neck pain than physiotherapy alone after more than 5 years. Patient self-ratings (global assessment) of treatment effect were also superior in the surgical group. No significant differences were found between the treatment groups regarding arm pain and health outcome. However, both groups demonstrated significant improvement compared with baseline for all outcome measures, although this result may in part be attributable to the natural course of the disease. ${ }^{22}$

\section{Treatment Effect Versus Natural Course}

Since the study did not have a control group that received no treatment, the influence of natural course alone cannot be evaluated. The results showing a 30- to $40-\mathrm{mm}$ reduction in pain intensity on the VAS and the self-rating of improvement by $93 \%$ of patients in the surgical group are well in line with other reports on surgical outcome. ${ }^{5,12,13,20,24}$ In patients suffering from soft disc herniation alone, Cesaroni and Nardi reported a residual pain level of $46 \mathrm{~mm}$ on the VAS and a score of $55 \%$ on the 
TABLE 3. Changes in neck disability, pain, and health scores at the 5- to 8-year follow-up, compared to baseline

\begin{tabular}{lccc}
\hline \multicolumn{1}{c}{ Parameter } & $\begin{array}{c}\text { Mean } \\
\text { Change }\end{array}$ & $95 \% \mathrm{Cl}$ & $\begin{array}{c}\mathrm{p} \\
\text { Value }\end{array}$ \\
\hline Surgical group & & & \\
\hline NDI score reduction in \% & 21 & $14-28$ & $<0.0001$ \\
\hline $\begin{array}{l}\text { VAS neck pain score reduction } \\
\text { in mm }\end{array}$ & 39 & $26-53$ & $<0.0001$ \\
\hline $\begin{array}{l}\text { VAS arm pain score reduction } \\
\text { in mm }\end{array}$ & 33 & $18-49$ & $<0.0001$ \\
\hline EQ-5D score increase & 0.29 & $0.13-0.45$ & 0.001 \\
\hline $\begin{array}{l}\text { EQ-VAS score increase in mm } \\
\text { Nonsurgical group }\end{array}$ & 29 & $19-39$ & $<0.0001$ \\
\hline $\begin{array}{l}\text { NDI score reduction in \% } \\
\text { VAS neck pain score reduction } \\
\text { in mm }\end{array}$ & 19 & $4-18$ & 0.004 \\
\hline $\begin{array}{l}\text { VAS arm pain score reduction } \\
\text { in mm }\end{array}$ & 19 & $7-30$ & 0.003 \\
\hline $\begin{array}{l}\text { EQ-5D score increase } \\
\text { EQ-VAS score increase in mm }\end{array}$ & 25 & $7-32$ & 0.004 \\
\hline * The significance of differences within groups was calculated using a paired \\
samples t-test.
\end{tabular}

NDI 1 year following various conservative treatments, ${ }^{6}$ but data for these patients reflected a worse condition at baseline than that indicated by corresponding data in the current study. The equivalent 1-year figures for residual pain among nonsurgically treated patients in the current study were $27-33 \mathrm{~mm}$ for VAS and $34 \%$ for NDI.

All nonsurgically treated patients had the possibility of undergoing surgery at their own request either during or after the study. The fact that only 8 patients (seven of those were followed up in this paper) did so may reflect the rather good results of physiotherapy alone, as well as an adaptation to living with the disease. A subgroup analysis of the same patient population, evaluating patient-related factors that could affect the outcome of both treatments, has recently been published. ${ }^{8}$

\section{Long-Term Outcomes}

The final results in the present study are consistent with, or even better than, the results at the 1- and 2-year

TABLE 4. Differences between surgical and nonsurgical groups at 5-8 years, compared to baseline

\begin{tabular}{lccc}
\hline \multicolumn{1}{c}{ Parameter } & $\begin{array}{c}\text { Mean } \\
\text { Difference }\end{array}$ & $95 \% \mathrm{Cl}$ & $\begin{array}{c}\mathrm{p} \\
\text { Value* }\end{array}$ \\
\hline NDI reduction in \% & 10 & $1-19$ & 0.03 \\
\hline $\begin{array}{l}\text { VAS neck pain score reduction } \\
\text { in mm }\end{array}$ & 21 & $4-37$ & 0.01 \\
$\begin{array}{l}\text { VAS arm pain score reduction } \\
\text { in mm }\end{array}$ & 14 & $5-32$ & 0.1 \\
\hline EQ-5D score increase & 0.15 & -0.04 to 0.34 & 0.1 \\
\hline EQ-VAS score increase in mm & 4 & -9 to 18 & 0.6 \\
\hline
\end{tabular}

* Significance was calculated using an independent samples t-test.
TABLE 5. Global self-assessment following treatment in patients with cervical radiculopathy*

\begin{tabular}{lcc}
\hline \multicolumn{1}{c}{ Answer } & Surgical Group & Nonsurgical Group \\
\hline Much better & 23 & 9 \\
\hline Better & 5 & 9 \\
\hline Unchanged & 1 & 6 \\
\hline Worse & 1 & 5 \\
\hline Much worse & 0 & 0 \\
\hline * Values represent the number of patients who responded to the question, "Af- \\
ter the treatment, my neck/arm problems are much better, better, unchanged, \\
worse, or much worse."
\end{tabular}

follow-ups, ${ }^{9}$ indicating that early treatment outcome can be expected to persist after more than 5 years. Moreover, only 3 patients in the nonsurgical group and none in the surgical group had surgery or reoperation after the 2-year follow-up, lending further support to this postulate. The greater effect of surgery on neck pain than arm pain may be surprising to some readers, and the rather low baseline pain intensity levels, especially for arm pain, may have affected this result as correlations have been made between high preoperative pain intensity and decreases in pain intensity after surgery.$^{16}$ There are earlier reports on a greater effect on neck pain than arm pain following surgery alone,, 7 but the majority document a greater effect on arm pain than neck pain in cohorts of operated patients, ${ }^{16,17,21,28}$ which in combination with the small number of patients in the present study should limit the conclusions made from this finding.

Regarding health outcome, no significant differences were found between treatment groups at 5-8 years. The EQ-5D levels of 0.80 in the surgical group and 0.67 in the nonsurgical group ( 0.51 and 0.53 at baseline) can be compared with a 1999 score of 0.83 in the Swedish national population at large and a 2006 score of 0.82 in the Stockholm population (both age-matched with mean age at baseline in the study plus 5 years). ${ }^{3,25}$ The 5- to 8-year EQ-VAS scores were 83 in the surgical group and 71 in the nonsurgical group (54 and 46 at baseline), compared with the age-matched national population score of 83 and the Stockholm score of 79. These scores suggest a high probability of regaining nearly normal health after undergoing treatment for cervical radiculopathy.

Another interesting finding as regards NDI, arm pain, and EQ-VAS is that surgically treated patients actually continued to improve between the 2-year and 5- to 8-year follow-ups, whereas nonsurgically treated patients showed no further improvement. However, there were no significant differences when comparing the 2 treatment groups, so these data should be interpreted with caution.

One possible explanation for the greater differences in certain outcome scores between the 2 groups 5-8 years after the start of the study, as compared with 2 years after, may be attributable to differences in statistical methodology. The multiple follow-ups analyzed in our earlier study required repeated-measures ANOVA for statistical analysis. To fill in missing values, multiple imputation was used before this analysis. The combination of these methods led to a slight decrease in statistically significant differences 
TABLE 6. Global self-assessment following treatment in patients with cervical radiculopathy: dichotomized responses and between-group comparison*

\begin{tabular}{|c|c|c|c|c|c|c|c|c|}
\hline \multicolumn{3}{|c|}{ Surgical Group } & \multicolumn{3}{|c|}{ Nonsurgical Group } & \multicolumn{3}{|c|}{ Group Comparison } \\
\hline Worse & Better & Risk† & Worse & Better & Risk† & $\mathrm{RR}$ & $95 \% \mathrm{Cl}$ & $p$ Valuef \\
\hline 2 & 28 & 0.93 & 11 & 18 & 0.62 & 1.5 & $1.11-2.01$ & 0.005 \\
\hline
\end{tabular}

Better = better/much better; worse = unchanged/worse/much worse.

* Values represent the number of patients, unless indicated otherwise.

$\dagger$ Risk within each group.

$\ddagger$ Tested using z-statistics.

between the analyzed groups compared with the statistics used in the present study. Other than this, no specific explanation for the somewhat unusual ongoing improvement among operated patients after 2 years can be obtained from the study.

To avoid bias as far as possible, intention to treat analysis was used for all statistical calculations. As 7 patients crossed over from nonsurgical to surgical treatment during the study, an "as treated" analysis putting these patients into the surgical group could also be done. This did not significantly change the results for pain, global assessment, or EQ-5D, and thus strengthening the validity of these re-

TABLE 7. Changes in outcome measures between 2 and 5-8 years: within-group differences and between-group differences

\begin{tabular}{|c|c|c|c|}
\hline Parameter & $\begin{array}{l}\text { Mean } \\
\text { Change }\end{array}$ & $95 \% \mathrm{Cl}$ & $\begin{array}{c}\mathrm{p} \\
\text { Value }^{*}\end{array}$ \\
\hline \multicolumn{4}{|l|}{$\begin{array}{l}\text { Change btwn } 2 \& 5-8 \text { yrs, surgical } \\
\text { group }\end{array}$} \\
\hline NDI score reduction in \% & 5 & $0-10$ & 0.03 \\
\hline $\begin{array}{l}\text { VAS neck pain score reduction } \\
\text { in } \mathrm{mm}\end{array}$ & 4 & -1 to 10 & 0.1 \\
\hline $\begin{array}{l}\text { VAS arm pain score reduction } \\
\text { in } \mathrm{mm}\end{array}$ & 11 & $2-20$ & 0.2 \\
\hline EQ-5D score increase & 0.1 & $0-0.2$ & 0.07 \\
\hline EQ-VAS score increase in $\mathrm{mm}$ & 9 & $2-17$ & 0.02 \\
\hline \multicolumn{4}{|l|}{$\begin{array}{l}\text { Change btwn } 2 \text { \& 5-8 yrs, nonsurgical } \\
\text { group }\end{array}$} \\
\hline NDI score reduction in \% & 0 & -5 to 4 & 0.9 \\
\hline $\begin{array}{l}\text { VAS neck pain score reduction } \\
\text { in } \mathrm{mm}\end{array}$ & 3 & -5 to 11 & 0.5 \\
\hline $\begin{array}{l}\text { VAS arm pain score reduction } \\
\text { in } \mathrm{mm}\end{array}$ & 1 & -9 to 12 & 0.8 \\
\hline EQ-5D score increase & 0.01 & -0.1 to 0.1 & 0.8 \\
\hline EQ-VAS score increase in mm & 1 & -4 to 7 & 0.6 \\
\hline \multicolumn{4}{|l|}{$\begin{array}{l}\text { Change btwn } 2 \text { \& } 5-8 \text { yrs, surgical vs } \\
\text { nonsurgical }\end{array}$} \\
\hline NDI score reduction in \% & 5 & -1 to 12 & 0.09 \\
\hline VAS neck pain reduction in $\mathrm{mm}$ & 2 & -8 to 11 & 0.7 \\
\hline VAS arm pain reduction in mm & 9 & -4 to 23 & 0.2 \\
\hline EQ-5D score increase & 0.1 & -0.1 to 0.2 & 0.2 \\
\hline EQ-VAS score increase in $\mathrm{mm}$ & 8 & -1 to 17 & 0.09 \\
\hline
\end{tabular}

* Significance for paired differences within groups was calculated using a paired samples t-test. Significance for differences between surgical and nonsurgical groups was calculated using an independent samples t-test. sults, although the statistically significant difference in NDI between groups at 5-8 years no longer remained ( $p$ $=0.14$ ). The reason for this finding is unclear, but an effect of the more skewed distribution of patients in the 2 groups using this method cannot be ruled out.

\section{Adjacent Level Symptoms}

In a Kaplan-Meier survivorship analysis, Hilibrand et al. calculated the risk of symptomatic adjacent-level disease 5 years after ACDF as $14 \% .^{14}$ We had planned to analyze the frequency of adjacent-level disease in the present study, but unfortunately the number of patients became too small for such an analysis; therefore, one cannot rule out the possibility that patients who report improvement compared with baseline may still have symptoms from adjacent levels. Nevertheless, the continuing improvement seen among operated patients between 2 and 5-8 years suggests that the widespread onset of radicular symptoms from adjacent disc levels due to surgical fusion is unlikely. Recently published reports suggest a 6\%-9\% rate of adjacent-level disease requiring additional surgery $2.5-5$ years after ACDF. ${ }^{15,23,26}$ Our data are small, but they contain no reoperations of surgically treated patients; we believe standard criteria for the need of secondary surgery were used.

\section{Study Limitations}

The main limitation of this study is the small sample size. Despite our efforts to use wide inclusion criteria and a long inclusion period, we must conclude that this type of randomization places rather high demands on patients and is therefore difficult to accomplish. Given the small study population, Type II errors cannot be ruled out. A true power analysis before the study was difficult as the studies needed to base the calculations on were lacking. The post hoc power for global assessment and neck pain was over $80 \%$, for NDI it was $62 \%$, but for arm pain and EQ-5D it was only between $30 \%$ and $40 \%$ based on the true spread and group differences; however, post hoc results must be interpreted with caution. Another limitation is the difference in baseline characteristics between the study participants and the patients who chose not to enter the study. The participants had a significantly longer duration of neck symptoms and lower pain levels than the nonparticipants. These limitations should be considered before generalizing the results. Nevertheless, we still believe that the study, because of its unique design, may provide important information regarding the treatment of cervical radiculopathy. 


\section{Summary and Clinical Recommendations}

In summary, it is reasonable to recommend a trial of structured physiotherapy in the early phase of cervical radiculopathy before making any surgical decision. However, for patients who have substantial residual symptoms, ACDF presents a good alternative for greater and more rapid improvement, which can also be expected to last at least throughout a 5- to 8-year time span. The optimal timing for surgery remains to be determined. ${ }^{2}$ This study also indicates that, compared with a structured physiotherapy program, surgery's potential to relieve neck pain may be at least as good as it is to relieve arm pain, which we believe may be contrary to the opinion held by many cervical spine surgeons.

\section{Conclusions}

In this prospective randomized study of 5- to 8-year outcomes of surgical versus nonsurgical treatment in patients with cervical radiculopathy, ACDF combined with physiotherapy reduced neck disability and neck pain more effectively than physiotherapy alone. Self-rating by patients as regards treatment outcome was also superior in the surgery group. No significant differences were seen between the 2 groups as regards arm pain and health outcome.

\section{References}

1. Ackelman BH, Lindgren U: Validity and reliability of a modified version of the Neck Disability Index. J Rehabil Med 34:284-287, 2002

2. Alentado VJ, Lubelski D, Steinmetz MP, Benzel EC, Mroz TE: Optimal duration of conservative management prior to surgery for cervical and lumbar radiculopathy: a literature review. Global Spine J 4:279-286, 2014

3. Björk S, Norinder A: The weighting exercise for the Swedish version of the EuroQol. Health Econ 8:117-126, 1999

4. Burkhardt JK, Mannion AF, Marbacher S, Dolp PA, Fekete TF, Jeszenszky D, et al: A comparative effectiveness study of patient-rated and radiographic outcome after 2 types of decompression with fusion for spondylotic myelopathy: anterior cervical discectomy versus corpectomy. Neurosurg Focus 35(1):E4, 2013

5. Cauthen JC, Kinard RE, Vogler JB, Jackson DE, DePaz OB, Hunter OL, et al: Outcome analysis of noninstrumented anterior cervical discectomy and interbody fusion in 348 patients. Spine (Phila Pa 1976) 23:188-192, 1998

6. Cesaroni A, Nardi PV: Plasma disc decompression for contained cervical disc herniation: a randomized, controlled trial. Eur Spine J 19:477-486, 2010

7. Davis RJ, Kim KD, Hisey MS, Hoffman GA, Bae HW, Gaede $\mathrm{SE}$, et al: Cervical total disc replacement with the Mobi-C cervical artificial disc compared with anterior discectomy and fusion for treatment of 2-level symptomatic degenerative disc disease: a prospective, randomized, controlled multicenter clinical trial: clinical article. J Neurosurg Spine 19:532-545, 2013

8. Engquist M, Löfgren H, Öberg B, Holtz A, Peolsson A, Söderlund A, et al: Factors affecting the outcome of surgical versus nonsurgical treatment of cervical radiculopathy: a randomized, controlled study. Spine (Phila Pa 1976) 40:1553-1563, 2015

9. Engquist M, Löfgren H, Öberg B, Holtz A, Peolsson A, Söderlund A, et al: Surgery versus nonsurgical treatment of cervical radiculopathy: a prospective, randomized study com- paring surgery plus physiotherapy with physiotherapy alone with a 2-year follow-up. Spine (Phila Pa 1976) 38:17151722,2013

10. EuroQol Group: EuroQol-a new facility for the measurement of health-related quality of life. Health Policy 16:199_ 208, 1990

11. Gore DR, Sepic SB: Anterior discectomy and fusion for painful cervical disc disease. A report of 50 patients with an average follow-up of 21 years. Spine (Phila Pa 1976) 23:2047-2051, 1998

12. Hamburger C, Festenberg FV, Uhl E: Ventral discectomy with PMMA interbody fusion for cervical disc disease: longterm results in 249 patients. Spine (Phila Pa 1976) 26:249255,2001

13. Hermansen A, Hedlund R, Vavruch L, Peolsson A: A comparison between the carbon fiber cage and the Cloward procedure in cervical spine surgery: a ten- to thirteen-year follow-up of a prospective randomized study. Spine (Phila Pa 1976) 36:919-925, 2011

14. Hilibrand AS, Carlson GD, Palumbo MA, Jones PK, Bohlman HH: Radiculopathy and myelopathy at segments adjacent to the site of a previous anterior cervical arthrodesis. $\mathbf{J}$ Bone Joint Surg Am 81:519-528, 1999

15. Lee JC, Lee SH, Peters C, Riew KD: Risk-factor analysis of adjacent-segment pathology requiring surgery following anterior, posterior, fusion, and nonfusion cervical spine operations: survivorship analysis of 1358 patients. J Bone Joint Surg Am 96: 1761-1767, 2014

16. Lied B, Roenning PA, Sundseth J, Helseth E: Anterior cervical discectomy with fusion in patients with cervical disc degeneration: a prospective outcome study of 258 patients (181 fused with autologous bone graft and 77 fused with a PEEK cage). BMC Surg 10:10, 2010

17. Löfgren H, Engquist M, Hoffmann P, Sigstedt B, Vavruch L: Clinical and radiological evaluation of trabecular metal and the Smith-Robinson technique in anterior cervical fusion for degenerative disease: a prospective, randomized, controlled study with 2-year follow-up. Eur Spine J 19:464-473, 2010

18. Noriega DC, Kreuger A, Brotat M, Ardura F, Hernandez R, Muñoz MF, et al: Long-term outcome of the Cloward procedure for single-level cervical degenerative spondylosis. Clinical and radiological assessment after a 22-year mean followup. Acta Neurochir (Wien) 155:2339-2344, 2013

19. Peolsson A, Söderlund A, Engquist M, Lind B, Löfgren H, Vavruch L, et al: Physical function outcome in cervical radiculopathy patients after physiotherapy alone compared with anterior surgery followed by physiotherapy: a prospective randomized study with a 2-year follow-up. Spine (Phila Pa 1976) 38:300-307, 2013

20. Persson LC, Carlsson CA, Carlsson JY: Long-lasting cervical radicular pain managed with surgery, physiotherapy, or a cervical collar. A prospective, randomized study. Spine (Phila Pa 1976) 22:751-758, 1997

21. Phillips FM, Lee JY, Geisler FH, Cappuccino A, Chaput CD, DeVine JG, et al: A prospective, randomized, controlled clinical investigation comparing PCM cervical disc arthroplasty with anterior cervical discectomy and fusion. 2-year results from the US FDA IDE clinical trial. Spine (Phila Pa 1976) 38:E907-E918, 2013

22. Radhakrishnan K, Litchy WJ, O'Fallon WM, Kurland LT: Epidemiology of cervical radiculopathy. A population-based study from Rochester, Minnesota, 1976 through 1990. Brain 117:325-335, 1994

23. Song KJ, Choi BW, Kim JK: Adjacent segment pathology following anterior decompression and fusion using cage and plate for the treatment of degenerative cervical spinal diseases. Asian Spine J 8:720-728, 2014

24. Sugawara T, Itoh Y, Hirano Y, Higashiyama N, Mizoi K: Long term outcome and adjacent disc degeneration after an- 
terior cervical discectomy and fusion with titanium cylindrical cages. Acta Neurochir (Wien) 151:303-309, 2009

25. Sun S, Irestig R, Burström B, Beijer U, Burström K: Healthrelated quality of life (EQ-5D) among homeless persons compared to a general population sample in Stockholm County, 2006. Scand J Public Health 40:115-125, 2012

26. van Eck CF, Regan C, Donaldson WF, Kang JD, Lee JY: The revision rate and occurrence of adjacent segment disease after anterior cervical discectomy and fusion: a study of 672 consecutive patients. Spine (Phila Pa 1976) 39:2143-2147, 2014

27. Vernon H: The Neck Disability Index: state-of-the-art, 19912008. J Manipulative Physiol Ther 31:491-502, 2008

28. Vernon H, Mior S: The Neck Disability Index: a study of reliability and validity. J Manipulative Physiol Ther 14:409415, 1991

29. Wang X, Chen Y, Chen D, Yuan W, Chen X, Zhou X, et al: Anterior decompression and interbody fusion with BAK/C for cervical disc degenerative disorders. J Spinal Disord Tech 22:240-245, 2009

\section{Disclosures}

The study was financially supported by the Medical Research
Council of Southeast Sweden. The work of Markus Engquist was financially supported by Futurum, the Academy for Healthcare, Jönköping County Council.

\section{Author Contributions}

Conception and design: all authors. Acquisition of data: Engquist, Löfgren, Holtz, Vavruch, Lind. Analysis and interpretation of data: Engquist. Drafting the article: Engquist, Öberg. Critically revising the article: Engquist, Löfgren, Oberg, Peolsson, Söderlund, Vavruch, Lind. Reviewed submitted version of manuscript: all authors. Approved the final version of the manuscript on behalf of all authors: Engquist. Statistical analysis: Engquist. Study supervision: Engquist.

\section{Supplemental Information}

\section{Previous Presentations}

Portions of this work were presented in abstract form at the annual meeting of the European Section of the Cervical Spine Research Society held in London, United Kingdom, on May 27, 2015.

\section{Correspondence}

Markus Engquist, Department of Orthopaedics, Ryhov Hospital, S-551 85 Jönköping, Sweden. email: markus.engquist@rjl.se. 